\title{
Semantic virtual environments
}

Multimedia Tools and Applications gratefully acknowledges the editorial work of the scholars listed below on the special issue entitled "Semantic Virtual Environments."

Of 31 papers submitted to this issue, 18 were eventually accepted after a stringent peerreview process.

\section{Corresponding Guest Editor}

Prof. Fotis Liarokapis

Masaryk University, Czech Republic

Email: fliarokapis@gmail.com

\section{Guest Editor}

Prof. Anastasios D. Doulamis

National Technical University of Athens, Greece

Email: adoulam@cs.ntua.gr

Publisher's note Springer Nature remains neutral with regard to jurisdictional claims in published maps and institutional affiliations. 